\title{
Computational fluid dynamics investigation of turbulent separated flows in axisymmetric diffusers
}

\author{
Dheeraj Sagar, Akshoy Ranjan Paul*, Anuj Jain \\ Department of Applied Mechanics, Motilal Nehru National Institute of Technology, Allahabad, INDIA \\ *Corresponding Author: e-mail: arpaul2k@yahoo.co.in, Tel +91-532-2271212, Fax.+91-532-2271200
}

\begin{abstract}
This study discusses about numerical investigation of the turbulent flow $\left(\mathrm{Re}=5 \times 10^{4}\right)$ through axisymmetric expansion having different diffuser half-angles $\left(6^{\circ}<\alpha<90^{\circ}\right)$ experimentally found in literature. The diffuser inlet flow is a two-dimensional, turbulent, and fully-developed one. Commercial code GAMBIT is used for geometry and grid generation and FLUENT 6.3 is used for flow simulation. Grid cells are selected based on ramp angle, which ranges from 99500 to 135000 . Space 3D formulation with implicit function approach is adopted in the solution scheme along with RNG $k-\varepsilon$ turbulence model in consideration. The main attention is given to flow separation as well as to downstream reattachment. It is found that the pressure distribution becomes uniform and separation is getting delayed as $\alpha$ decrease.
\end{abstract}

Keywords: Axisymetric diffuser, turbulent flow, flow separation, reattachment, computational fluid dynamics (CFD).

\section{Introduction}

The flow through axisymmetric expansion is one of the most commonplace examples of turbulent, separated flow fields in practical engineering situations. Wide-angle diffuser geometries appear in a variety of monitor and control devices in piping systems, while the $90^{\circ}$ diffuser or sudden expansion is normally found in piping junctions or weld ribs. The sudden expansion is also a common geometry in combustion chambers acting as a flame stabilizer or simply as a sudden dump diffuser .Although this interest in the flow has led to a significant number of experimental and numerical investigation of the flow fields and its influence on heat and mass transfer coefficients, there exists a lack of detailed knowledge about turbulence properties, especially in the recirculation regions of the flow.

The present study concentrates on systematically investigating the separated flow in an axisymmetric expansion having various diffuser half angles as shown in figure 1. This aims to contribute to the physics of flow separation, by computing the pressure coefficients measured along the axial coordinate for diffuser half-angles between $6^{\circ}$ and $90^{\circ}$. Different diffuser half angles $\left(6^{\circ}<\alpha<90^{\circ}\right)$ vary with the base length $(x)$ of diffuser and are listed in table-1. Starting the discussion from the sub critical $6^{\circ}$ configuration, it becomes evident that a pressure-induced separation starts inside of the diverging section of the diffusers as the half-angle increases. This onset of separation leads to a reorientation of the flow fields and, thus a different pressure distribution characteristic is available at the outlet of the diffuser. The main attention is given to flow separation and reattachment as well as to flow relaxation in the downstream reattachment. This investigation is aimed at analyzing the system of this separation phenomenon.

This paper was presented at the $5^{\text {th }}$ National Conference on Applicable Mathematics in Wave Mechanics and Vibrations (WMVC2010) held at Kakatiya University, Warangal, India, 13-15 March, 2010. 


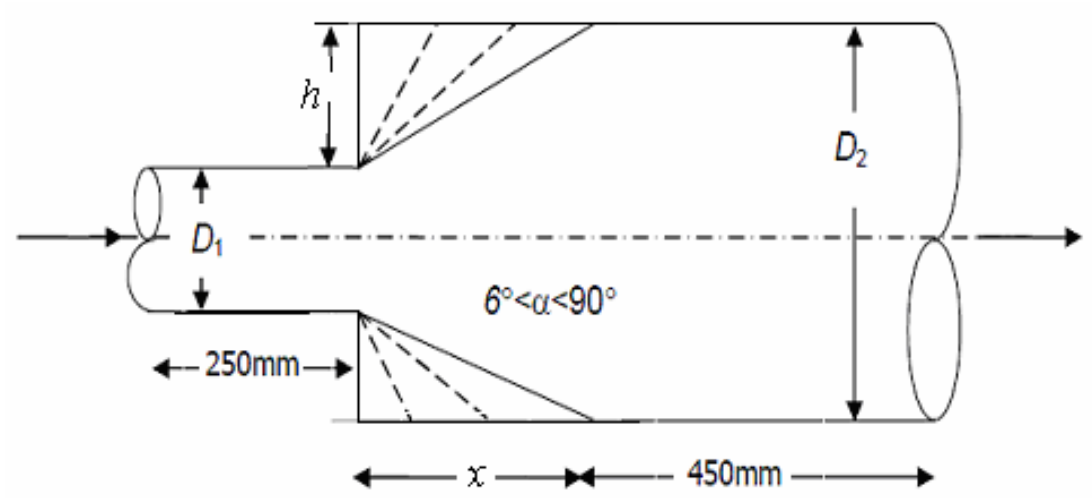

Figure 1. Schematic diagram of the axisymmetric expansion.

Table 1: Geometrical parameters of the axisymmetric diffuser

\begin{tabular}{ccc}
\hline Step height $(\boldsymbol{h}$ in $\mathbf{~ m m})$ & Half angle $\left(\boldsymbol{\alpha}^{\circ}\right)$ & Base length $(\boldsymbol{x}$ in $\mathbf{~ m m})$ \\
\hline 15 & 6 & 142.7 \\
\hline 15 & 10 & 85.0 \\
\hline 15 & 18 & 46.17 \\
\hline 15 & 90 & 0.0 \\
\hline
\end{tabular}

\section{Computational Methodology}

The diffuser inlet flow is considered as a two-dimensional, turbulent, and fully-developed one. The inlet velocity of air is kept as $14.61 \mathrm{~m} / \mathrm{s}$ and the corresponding Reynolds number is $5 \times 10^{4}$ based on the inlet cross-section of the diffuser. Initially threedimensional space formulation is carried out in a commercial geometry cum grid generation software- 'Gambit' for axisymmetric diffusers with various half angles keeping a constant area ratio of 1.6 for all the cases. The half angles and their corresponding mesh sizes are tabulated in table 2. Boundary layer is created with first grid point at $0.1 \mathrm{~mm}$ in order to capture the wall effect and separation. Hexahedral meshing is done so as to get structured meshed in the core region. Velocity-inlet boundary condition and pressure-outlet boundary condition were imposed at the inlet and outlet of the diffuser respectively. Renormalized group (RNG) $k-\varepsilon$ turbulence model is used for code validation.

The proper selection of turbulence models for any flow computation using CFD demands rapt attention. The $k-\varepsilon$ turbulence model belongs to the class of two-equation models, in which model transport equations are solved for two turbulence quantities $k$ and $\varepsilon$. The $k-\varepsilon$ model is arguably the simples complete turbulence model, and it has broadest range of applicability. It is incorporated in most commercial CFD codes, and has been applied to a diverse range of engineering problems (Pope, 2009). As is the case with all turbulence models, both the concepts and details evolved over time; but Jones and Launder (1972) are appropriately credited with developing the 'standard' $k-\varepsilon$ model, with Launder and Sharma (1974) providing improved values of the model constants. The term $\mu_{t}$ is called turbulent or eddy viscosity and is introduced in RANS modelling to describe the timeaveraged effects of the turbulent stress. According to the widely used two-equation $k-\varepsilon$ model, $\mu_{t}$ can be expressed as follows:

$$
\mu_{t}=\rho C_{\mu} \frac{k^{2}}{\varepsilon}
$$

where $C_{\mu}$ is a constant and $k$ and $\varepsilon$ are the local turbulent kinetic energy and its dissipation rate respectively. In order to close the model two other equations are required, namely the transport equations for $k$ and $\varepsilon$ :

$k$-equation:

$$
\frac{\left(\rho U_{i} k\right)}{\partial x_{i}}=\frac{\partial}{\partial x_{i}}\left[\left(\mu+\frac{\mu_{t}}{\sigma_{k}}\right) \cdot \frac{\partial k}{\partial x_{i}}\right]=P_{k}-\rho \varepsilon
$$


$\varepsilon$-equation:

$$
\frac{\partial\left(\rho U_{i} \varepsilon\right)}{\partial x_{i}}=\frac{\partial}{\partial x_{i}}\left[\left(\mu+\frac{\mu_{t}}{\sigma_{\varepsilon}}\right) \cdot \frac{\partial \varepsilon}{\partial x_{i}}\right]+C_{\varepsilon 1} \frac{\varepsilon}{k} P_{k}-C_{\varepsilon 2} \frac{\varepsilon^{2}}{k}
$$

In Eqs. 2 and 3, $P_{k}$ is the production rate of turbulent kinetic energy, which depends on the turbulent or eddy viscosity $\mu_{t}$ and the velocity distribution. Five closure coefficients according to Launder and Sharma (1974) are taken as

$$
C_{\mu}=0.09, C_{\varepsilon 1}=1.44, C_{\varepsilon 2}=1.92, \sigma_{k}=1.0, \sigma_{\varepsilon}=1.32
$$

These values may be not suitable for low Reynolds number flows, or in some local domains of high Reynolds number flows where the damping effect of the surfaces is prominent; in these cases, some corrections would be required. Launder (1990) and Hanjalić (1994) reported poor performance of 'standard' $k-\varepsilon$ model for a particular class of flows. To improve the performance, the renormalized group (RNG) method has been used to obtain the $k-\varepsilon$ equation from the Navier-Stokes equations (refer Yakhot and Orszag, 1986; Smith and Reynolds, 1992; Smith and Woodruff, 1998. Concerning this problem, Renormalization Group (RNG) model is gaining popularity for modelling internal flows; the difference between RNG and $k-\varepsilon$ models mainly results in the substitution of the constant $C_{\varepsilon 1}$ in Eq. 3 with the following expression:

$$
C_{\varepsilon 1}=C_{\varepsilon 1}^{0}-\frac{\eta\left(1-\eta / \eta_{0}\right)}{1+\beta \eta^{3}}
$$

where $C_{s 1}^{0} \approx 1.44, \eta_{0} \approx 4.4, \beta \approx 0.015$ and

$$
\eta=\frac{k}{\varepsilon} \sqrt{\frac{P_{k}}{\mu}}
$$

Through Eqs. 4 and 5, the production term in Eq. 3 is modified in such a way that it properly accounts for the larger dissipation rate experienced in the laminar regions near solid surfaces. Detailed information about the application of RNG model is available in Orszag et al. (1996), according to which the values of five closure coefficients stemming from RNG analysis are

$$
C_{\mu}=0.0845, C_{\varepsilon 1}=1.42, C_{\varepsilon 2}=1.68, \sigma_{k}=\sigma_{\varepsilon}=0.72
$$

In the RNG $k-\varepsilon$ model, there is also an additional term in the $\varepsilon$ equation, which is an ad hoc model, not derived from RNG theory. It is the term which is largely responsible for the difference in the performance of the standard and RNG models.

Turbulent mixing is largely suppressed by the proximity of a wall boundary and the $k-\varepsilon$ model however does not represent this effect and breaks down below the log layer. The turbulence energy $k$ certainly goes down to zero at the wall but fixing the unknown finite value of the $\varepsilon$ at wall is not so obvious.

A steady state based implicit solver is used to achieve convergence. Second-order upwind scheme was used for the discretization of all the equations to achieve higher accuracy in results. Velocity-pressure coupling was established by pressure-velocity correlation using a SIMPLE algorithm (Patankar, 1980). Under-relaxation factors were used for all equation to satisfy Scarborough condition (Fluent's user guide, 2006). Residuals were continuously monitored for continuity, $x$-velocity, $y$-velocity, $z$-velocity, $k$, and $\varepsilon$. Convergence of the solution was assumed when the values of all residuals goes below $10^{-6}$. Standard wall function was used to solve for the near wall treatment, as $y^{+}$is more than 30 in the whole domain.

Table 2: Mesh sizes for the computation of axisymmetric diffuser.

\begin{tabular}{ll}
\hline Half angle $\left(\boldsymbol{\alpha}^{\circ}\right)$ & No. of Cells \\
\hline 6 & 135,000 \\
\hline 10 & 112,500 \\
\hline 18 & 110,600 \\
\hline 90 & 99,500 \\
\hline
\end{tabular}




\section{Results and Discussion}

The commercially available finite-volume method based CFD solver 'FLUENT 6.3' is used for flow computation through axisymmetric diffuser. The CFD code is validated against the experimental data reported by Nitsche and Haberland (1989). Figure 2 shows the experimental and computational comparison of skin-friction coefficient $\left(C_{f}\right)$ for various half-angles of the diffuser. For low values of diffuser half angles (i.e., $\alpha=6^{\circ}$ and $10^{\circ}$ ), there is a qualitative agreement between experimental and computational results. However, quantitative matching is not appreciable. But for relatively high values of half angles (i.e., $\alpha=18^{\circ}$ and $90^{\circ}$ ), both qualitative and quantitative agreement between experimental and computational results are achieved. The error analysis shows that the uncertainty between the experimental and CFD values falls within $\pm 3.8 \%$ of $C_{f}$ values, which is pretty acceptable.

Since a large positive pressure gradient is built up along the flow direction down the diffuser length, the chances of flow separation is more in diffuser. When the flow can not spend energy to overcome the positive pressure gradient, the flow starts separating from the solid wall. Flow separation involves energy losses, which further deteriorates the performance of the diffuser. A careful monitoring of skin-friction coefficient $\left(C_{f}\right)$ gives an idea of flow separation within such axisymmetric diffuser. The zero $C_{f}$ value indicates the onset of separation and it continues till $C_{f}$ value becomes zero once again. The location of such flow separation can be identified and accordingly, measures can be taken to remove or at least delay the flow separation.

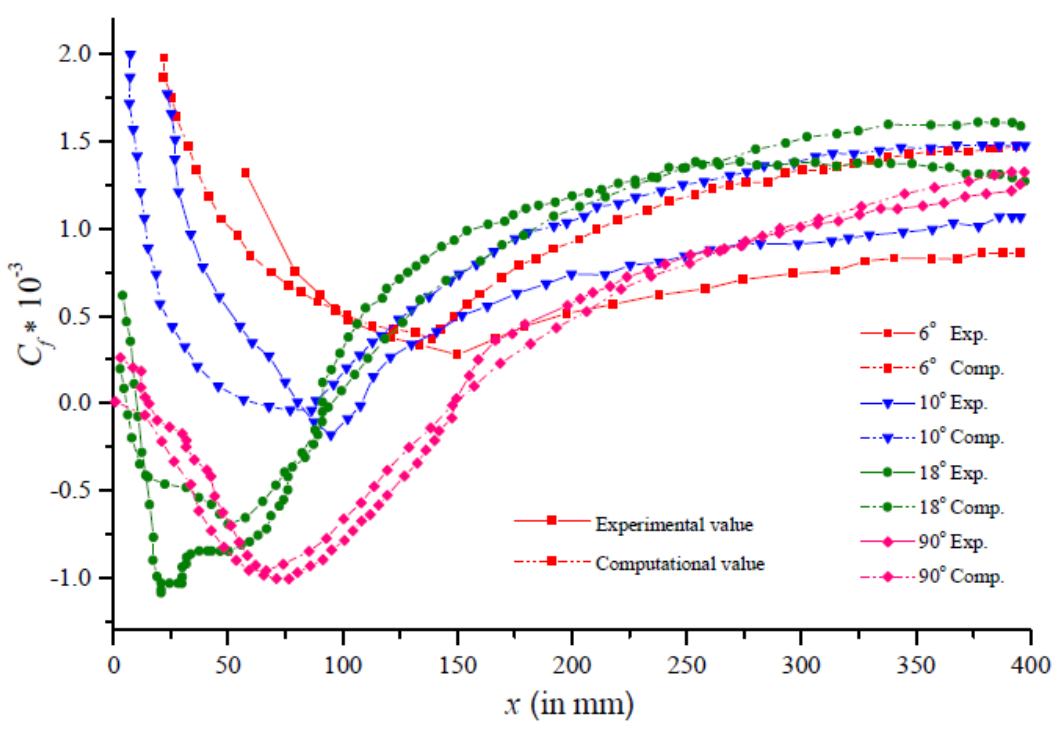

Figure 2. Experimental and computational comparison of skin-friction coefficient in axisymmetric diffuser.

The variation of non-dimensional reattachment length $\left(x_{r} / h\right)$ with diffuser half angle $\left(\alpha^{\circ}\right)$ is shown in figure 3. Initially, there is no separation for $6^{\circ}$ half angle diffuser, since $\left(x_{r} / h\right)=0$. But the separation is observed for $10^{\circ}\left(x_{r} / h=6.5\right)$ half-angle. From thereon, the reattachment length decreases till $18^{\circ}\left(\left(x_{r} / h=3.6\right)\right.$ and further increases sharply till $90^{\circ}\left(x_{r} / h=8.7\right)$.

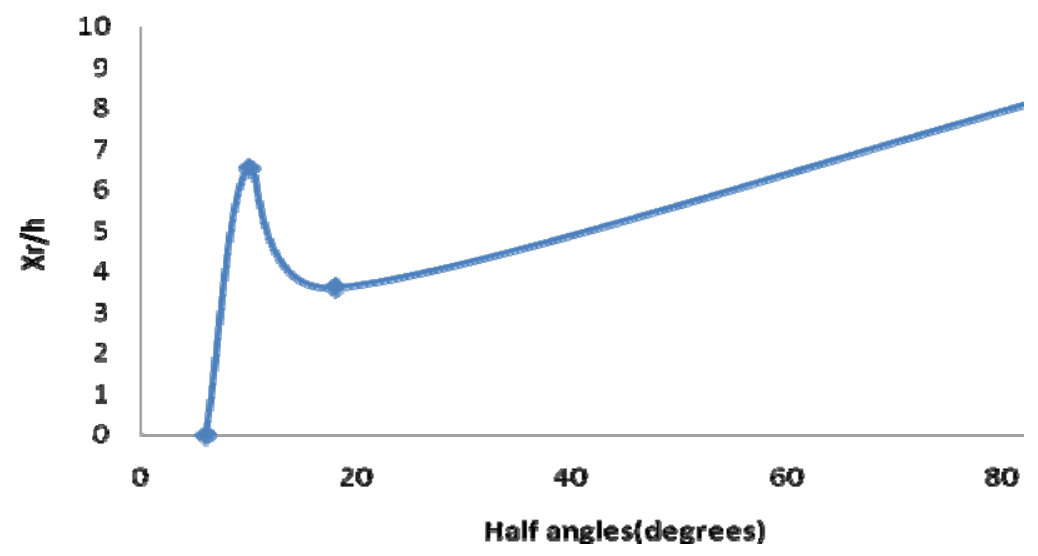

Figure 3. Reattachment length versus diffuser half angle. 


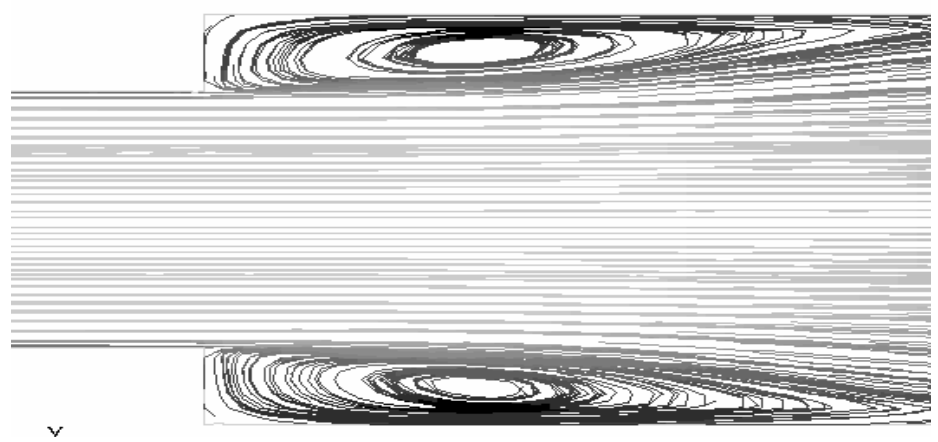

Figure 4. Streamlines for $90^{\circ}$ axisymmetric diffuser.

The flow separation and the reverse flow zone at both the corners and subsequent reattachment length for a $90^{\circ}$ axisymmetric diffuser can be better visualized by the plot of streamlines as shown in figure 4 .

\section{Conclusions}

The expansion of cross-sectional area of axisymmetric diffuser for various half angles show the transition of bulk flow into pressure induced separation and subsequent reattachment of flow at the downstream. The comparisons of the values of skinfriction coefficient for various half angles indicate a satisfactory agreement between the experiment and computation carried out with RNG $k-\varepsilon$ turbulence model. No separation is observed for the $6^{\circ}$ axisymmetric diffuser. Flow separation starts from $10^{\circ}$ axisymmetric diffuser and the maximum reattachment length $\left(x_{r}\right)$ length is computed as $130 \mathrm{~mm}$ for the $90^{\circ}$ axisymmetric diffuser.

\section{Nomenclature}

$\begin{array}{ll}C_{f} & \text { skin-friction coefficient of diffuser, } C_{f}=\tau_{w} / 0.5 \rho U_{\infty}^{2} \text {, dimensionless } \\ C_{\mu}, C_{\varepsilon 1}, C_{\varepsilon 2}, C_{\varepsilon 1}^{0} & \text { turbulence constants, diimensionless } \\ D_{1} & \text { inlet diameter of diffuser, mm } \\ D_{2} & \text { outlet diameter of diffuser, mm } \\ h & \text { step height of diffuser, } \mathrm{mm} \\ k & \text { turbulent kinetic energy, } \mathrm{m}^{2} / \mathrm{s}^{2} \\ P_{k} & \text { production rate of turbulent kinetic energy, } \mathrm{N} / \mathrm{m}^{2} \mathrm{~s} \\ u_{*} & \text { friction velocity at the nearest wall, } u_{*}=\sqrt{\tau_{w} / \rho}, \mathrm{m} / \mathrm{s} \\ U_{\infty} & \text { freestream velocity of air, mm } \\ x & \text { base length of diffuser along flow, mm } \\ x_{r} & \text { reattachment length, mm } \\ y & \text { distance to the nearest wall (normal to flow direction), } \mathrm{mm} \\ y^{+} & \text {dimensionless wall distance, } y^{+}=u_{*} y / v \\ \beta, \eta_{0}, \sigma_{k}, \sigma_{\varepsilon} & \text { turbulence constants, diimensionless } \\ \varepsilon & \text { turbulent kinetic energy dissipation rate, } \mathrm{m}^{2} / \mathrm{s}^{3} \\ v & \text { kinematic viscosity of fluid, } \mathrm{m}^{2} / \mathrm{s} \\ \rho & \text { density of fluid, kg/m } \\ \tau_{w} & \text { wall shear stress, } \mathrm{N} / \mathrm{m}^{2} \\ \mu_{t} & \text { turbulent or eddy dynamic viscosity, } \mathrm{Ns} / \mathrm{m}^{2}\end{array}$

\section{Acknowledgement}

The authors acknowledge Department of Science \& Technology, Govt. of India for providing necessary fund through DST-FIST programme to carry out this work. 


\section{References}

Fluent, User's Guide, CFD Software Package, Ver. 6.3, Fluent, Lebanon, NH, 2006.

Hanjalić, K., Advanced turbulence closure models: A view of current status and future prospects, J. of Heat and Fluid Flow, Vol. 15, 1994, pp. 178-203.

Launder, B.E. and B.I. Sharma, Application of the energy-dissipation model of turbulence to the calculation of flow near a spinning disc, Letters of Heat and Mass Transfer, Vol. 1, 1974, pp. 131-138.

Launder, B.E., Phenomenological modeling: present... and future?, In: J.L. Lumley (Ed.), Whither Turbulence? Turbulence at the Crossroads, Springer-Verlag, Berlin, 1990, pp. 439-485.

Nitsche, W. and C. Haberland, Turbulent separated flow in axisymmetric diffusers, In: K. Gersten (Ed.), Numerical Fluid Mechanics (Vol.40), Physics of Separated Flows: Numerical, Experimental, and Theoretical Aspects, Vieweg, Berlin, 1989, pp. 117-125.

Orszag, S.A., I. Staroselsky, W.S. Flannery and Y. Zhang, Introduction to renormalization group modeling of turbulence, In. T.B. Gatski, M.Y. Hussaini and J.L. Lumly (Eds.), Simulation and modeling of turbulent flows, Oxford Univ. Press, NY, Chapter 4, 1996, pp. 155-183.

Patankar, S. V., Numerical heat transfer and fluid flow, Taylor and Francis Publication, London, UK, 1980.

Pope, S.B., Turbulent Flows, 6th Reprint, Cambridge Univ. Press, NY, 2009, pp. 373-384.

Jones, W.P. and B.E. Launder, The prediction of laminarization with a two-equation model of turbulence, Int. J. of Heat and Mass Transfer, Vol. 15, 1972, pp. 301-314.

Smith, L.M. and W.C. Reynolds, On the Yakhot-Orszag renormalization group method for deriving turbulence statistics and models, Physics of Fluids, Vol. A4, 1992, pp. 364-390.

Smith, L.M. and S.L. Woodruff, Renormalization-group analysis of turbulence, Annual Review of Fluid Mechanics, Vol. 30, 1998, 275-310.

Yakhot, V. and Orszag, Renormalized group analysis of turbulence: I. Basic theory, J. of Scientific Computation, Vol. 1, 1986, pp. 3-51.

\section{Biographical notes}

Dheeraj Sagar has recently completed his M.Tech. in Fluids Engineering from Applied Mechanics department at Motilal Nehru National Institute of Technology, Allahabad, India. He is currently working as Assistant Professor in the Mechanical Engineering department of Invertis University in Bareilley, India. Earlier, he was involved in the flow control research group at MNNIT, Allahabad.

Akshoy Ranjan Paul is an Assistant Professor in the Department of Applied Mechanics, Motilal Nehru National Institute of Technology, Allahabad, India. He has received M. E. degree from Jadavpur University, Kolkata, India in 2002. He has more than nine years of experience in teaching and research. His current research area includes internal flow aerodynamics, flow control and turbulence modeling. He has published four textbooks and many research papers in national and international conferences and journals. He also visited a few technical universities in UK, Denmark, and Sweden for academic purposes and technical training.

Pritanshu Ranjan is presently working as a visiting faculty member in Applied Mechanics department at Motilal Nehru National Institute of Technology, Allahabad, India. He did his M.Tech. in Fluids Engineering from the same department. He is involved in the flow control research group in the institute. He has published a few research papers in national and international conferences and journals.

Received September 2010

Accepted March 2011

Final acceptance in revised form March 2011 